\title{
Improvement of Turbine Performance by Streamwise Boundary Layer Fences
}

\author{
M. Govardhan ${ }^{\dagger}$ and P.K. Maharia \\ Thermal Turbomachines Laboratory, Department of Mechanical Engineering \\ Indian Institute of Technology Madras, Chennai 600 036, India \\ †Corresponding AuthorEmail: gova@iitm.ac.in
}

(Received October 10, 2010; accepted March 27, 2011)

\begin{abstract}
In the present investigations, effect of streamwise end wall fences on the performance improvement of a turbine is studied. The fences with heights of $12 \mathrm{~mm}, 16 \mathrm{~mm}$ were attached normal to the end wall and at a half pitch away from the blades. A miniaturized pressure probe was traversed at the exit of the cascade from midspan to the end wall at 26 locations covering more points in the end wall region. For each spanwise location, the probe was traversed in the pitchwise direction for more than 25 points covering one blade pitch. The boundary layer fence near the end wall remains effective in changing the path of pressure side of leg of horseshoe and weaken the cross flow. The overturn in flow has reduced near the end wall when fences are incorporated while outside end wall and in loss core region, it underturns slightly as result of reduction in secondary loss. The total loss is reduced by $15 \%, 25 \%$ for fences of height $12 \mathrm{~mm}$, and $16 \mathrm{~mm}$ respectively. The corresponding change was obtained in the drag and lift coefficients.
\end{abstract}

Keywords: Boundary layer fences, Performance, Passage vortex, Loss core, Lift and drag coefficients.

\section{NOMENCLATURE}

$\begin{array}{ll}A R & \begin{array}{l}\text { Aspect ratio } \\ \mathrm{C}\end{array} \\ & \begin{array}{l}\text { Total velocity of fluid at any given } \\ \text { location }\end{array} \\ C_{D} & \text { Drag coefficient } \\ C_{L} & \text { Lift coefficient } \\ C_{h} & \text { Blade chord } \\ \mathrm{e} & \text { Blade axial chord } \\ \mathrm{h} & \text { Fence height, blade span } \\ \mathrm{P} & \text { Total pressure at any given location } \\ P_{S} & \text { Static pressure at any given location } \\ S & \text { Spacing (mm) }\end{array}$

\section{INTRODUCTION}

The flow through a turbine is three dimensional with complex interaction of many factors such as pressure gradients, turbulence, horseshoe, and passage vortices. The three dimensional flows irreversibly produce secondary losses of considerable magnitude and enables fluid flow to deviate from the potential flow prediction in the end wall region. This reduces the work transfer in the subsequent stages. A complete understanding of complex three dimensional flows and losses would certainly be helpful in improving the turbine performance. The development of secondary flows through the blade passage in a turbine cascade and their overall interpretation of the vortex flow pattern are shown in Fig. 1 (Wang et al. 1997). Reduction of secondary flow losses has been investigated by many
$X \quad$ Distance along the cascade flow direction

$Y \quad$ Distance normal to the cascade flow direction

$Y_{\text {Local }}$ Local pressure loss coefficient

$\mathrm{Z} \quad$ Longitudinal distance along the span of the blade

$\alpha_{1 b} \quad$ Blade inlet angle

$\alpha_{2 b} \quad$ Blade exit angle

$\gamma \quad$ Stagger angle

investigators. They could be classified into active and passive methods. Passive method means reducing loss by making geometrical modifications and active methods means changing flow features such as boundary layers, by local blowing of air. In the present study only geometrical modification has been made, hence only passive methods are discussed. Secondary flow losses are investigated in the present study by fixing streamwise boundary layer fences on the end wall surface.

The streamwise fences effectively prevent the movement of the flow field in the end wall region. At the leading edge, the flow field splits into two sections and moves either side of the blade. Fences prevent the movement of pressure side leg of horseshoe vortex towards the suction side, and effectively reduce the 


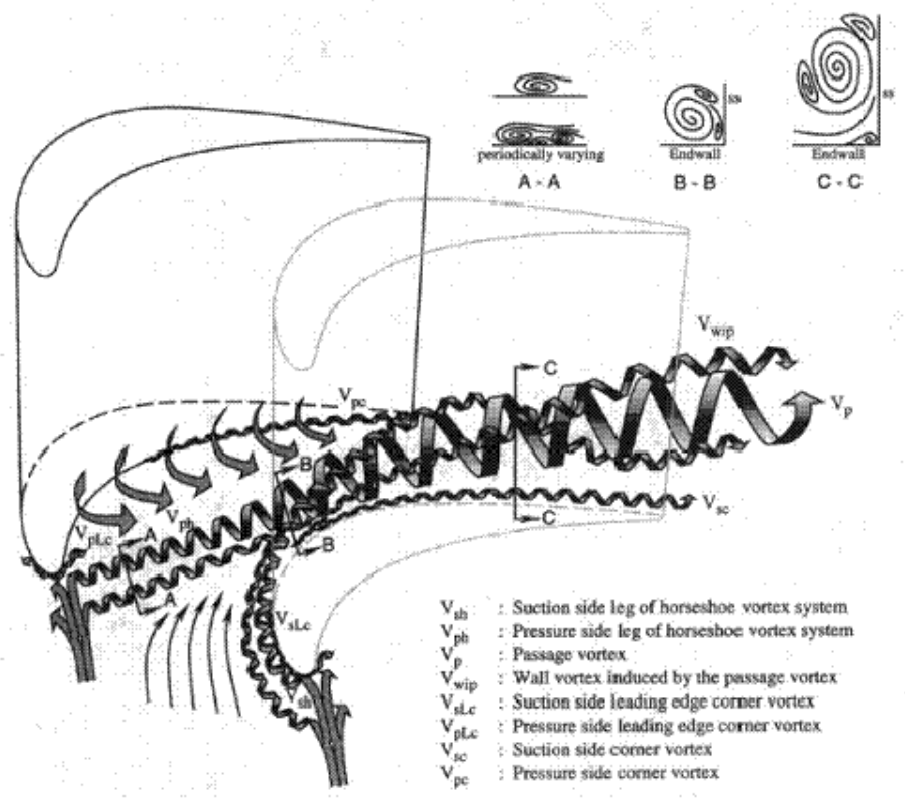

Fig. 1. Interpretation of the vortex flow pattern (Wang et al. 1997)

influence of passage and corner vortices on the flow near the end wall region. Kawai et al. (1994) have done few experiments on measurement of total pressure losses and three dimensional flow velocities for five different heights and seven different pitchwise locations of the fences. They have suggested that the fences were most effective when the height of the fence is $1 / 3$ of the inlet boundary layer thickness and located half a pitch away from the blades. A critical fence height above which the fence traps the pressure side legs of horseshoe vortices was found, and the optimum fences proved to be fences of the minimum critical height.

Moon and Koh (2001) investigated numerically the effect of height of fences (placed in the middle of the cascade on end wall) on the flow. Development of counter-rotating streamwise vortex was reported inside the blade passage. This was maximum for $\delta / 3 \mathrm{~mm}$ height case. Based on vorticity contours, they concluded that $\delta / 3 \mathrm{~mm}$ height fence is optimum. No quantitative results showing the effect of counter rotating vortex were presented. Aunapu et al. (2000) performed tests on the end wall fence. The fence length was modified with $30 \%$ from the upstream end and $20 \%$ from the downstream end. It was concluded that vortex remains away from the blade and doesn't climb the blade and its strength greatly decreased from the baseline case. Total pressure loss increased by about $30 \%$ with fence, but the combined coefficient of secondary kinetic energy (CSKE) and total pressure loss coefficient were $10 \%$ lower with fence than in baseline case.

Govardhan et al. (2006) applied streamwise fences on end wall of an impulse turbine blade cascade with a fence of $0.7 \mathrm{~mm}$ thickness. Flow visualisation was made using oil flow pattern. One unique feature in their visualisation was the formation of two separation saddle points near the leading edge, as only one saddle point has been reported in most of the turbine cascade
experiments.Chung and Simon (1993) haven studied effectiveness of the gas turbine end wall fences in secondary flow control at elevated free stream turbulence levels. They have concluded that a boundary layer fence on the end wall remains effective in changing the path of the horseshoe vortex and reducing the influence of the vortex on the flow near the suction wall at the high free stream turbulence level. The fence is more effective in reducing the secondary flow for the high turbulence case than for low turbulence intensity case, probably because the vortex which has been deflected into core flow diffuses and dissipates faster in the more turbulent flow.

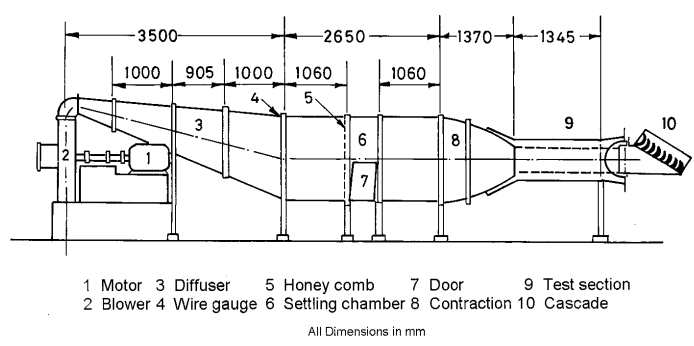

Fig. 2. Schematic of two-dimensional linear turbine cascade tunnel

The objective of the present investigations is to study the effect of streamwise boundary layer fences in reducing the secondary flow and associated pressure losses

\section{EXPERIMENTAL FACILITY AND INSTRUMENTATION}

All the experimental investigations described in this report were carried out on a two-dimensional linear cascade tunnel (Fig. 2). The two-dimensional low speed cascade tunnel is a pressure operated type in which air is compressed by a blower and is forced through the test section where the cascade of blades is installed. 
The tunnel consists of diffuser, settling chamber, contraction cone, test section. For supplying the air to the cascade, a centrifugal blower is used, driven by a 24 $\mathrm{kW}$ D.C. motor. The volume flow rate through the tunnel was $3.5 \mathrm{~m}^{3} / \mathrm{s}$ at a pressure rise of about $5000 \mathrm{~Pa}$. The arrangement of the blade with all the dimensions is shown in Fig. 3. Table 1 gives the details of the blade profile.

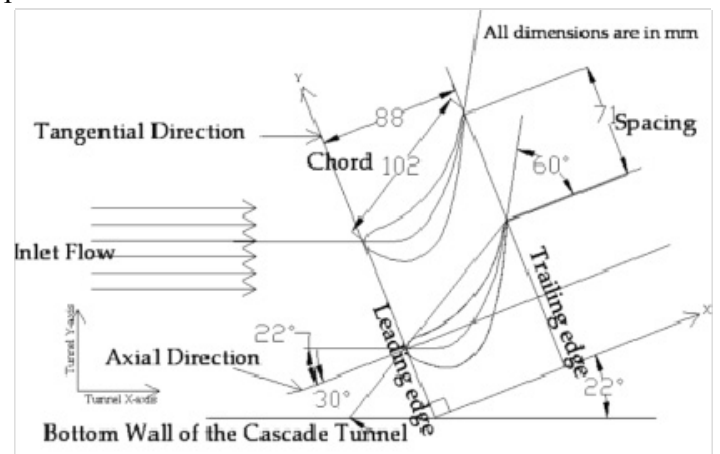

Fig. 3. Cascade arrangement

Table 1 The details of blade profile

\begin{tabular}{|l|l|}
\hline Blade chord, ch & $102.5 \mathrm{~mm}$ \\
\hline Blade axial chord, $\mathrm{e}$ & $88.32 \mathrm{~mm}$ \\
\hline Blade exit angle, $\alpha_{2 \mathrm{~b}}$ & $-60^{\circ}$ \\
\hline Blade inlet angle, $\alpha_{1}$ & $22^{\circ}$ \\
\hline Incidence angle, $\mathrm{i}$ & $0^{0}$ \\
\hline Blade spacing, $\mathrm{S}$ & $71 \mathrm{~mm}$ \\
\hline Blade height, $\mathrm{h}$ & $400 \mathrm{~mm}$ \\
\hline Blade stagger angle, $\gamma$ & $-30^{0}$ \\
\hline Blade aspect ratio, AR & 3.902 \\
\hline Space-chord ratio, $\mathrm{s} / \mathrm{ch}$ & 0.6927 \\
\hline Number of blades, $\mathrm{Z}$ & 7 \\
\hline
\end{tabular}

\subsection{Streamwise Fences}

The streamwise fences used in the present study were made of $0.6 \mathrm{~mm}$ thick brass sheet. The heights of the fences were $12 \mathrm{~mm}$ and $16 \mathrm{~mm}$ respectively. The fences were designed such that the curvature of the fences and stagger angles were maintained same as that of the blade camber line. The fences were fixed normal to the end wall region and at half pitch away from the blades. The fences were sharpened at their leading edge and trailing edge regions and were fixed to the end wall by using adhesive. A schematic of the fence arrangement is shown in Fig. 4.

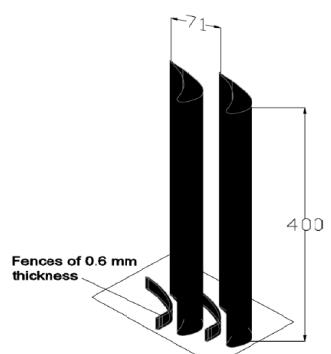

Fig. 4. Schematic of fences

A traversing mechanism allowed a miniaturized fivehole pressure probe (head diameter $2.4 \mathrm{~mm}$ ) to move in spanwise and pitchwise directions as well as in rotary motion about its longitudinal axis. A slot was made normal to the cascade flow direction in top plate for the movement of traverse mechanism.

A digital type micro-manometer (type FC 012, Furness Controls Ltd., UK) together with a 20 channel scanning box (type FC 011, Furness Controls Ltd., UK) was used for recording the pressures sensed by the probe. The scanning box facilitates reading 20 pressures sequentially without disturbing the connection of the sensor.

The probe was traversed in the spanwise direction from midspan to end wall region at 26 locations with more measurement points in the end wall region. For each spanwise location, the probe was traversed in the pitchwise direction at more than 25 locations covering one blade pitch. More readings were obtained in the wake zone of the blade. For the present investigations, the flow studies were made at the exit of the cascade as well as on the blade tip surface. Using total and static pressure values along with the yaw and pitch angles, the flow velocity and its three components in axial, pitchwise and spanwise directions were determined. The Reynolds number based on chord and exit velocity was maintained at $1.5 \times 10^{5}$.

\section{Results AND Discussion}

The results obtained from the experimenal investigation on a two dimensional linear cascade using $82^{\circ}$ deflection turbine blades are presented and discussed. The results with a particular reference to reduction in secondary losses in a turbine cascade using streamwise fences are highlighted.

\subsection{Local Loss Coefficient}

The local loss coefficient is calculated as the difference between midspan inlet total pressure and local total pressure at each location downstream of the cascade, non-dimensionalised with the dynamic pressure based on pitch and spanwise mass averaged velocity.

$Y_{\text {local }}=\frac{2\left(P_{01}-P_{02}\right)}{\rho C_{2}^{2}}$

The inlet total pressure was obtained at $X / e=-0.4$ and downstream survey was conducted at $X / e=1.06$ where $\mathrm{X}$ is the distance in cascade axial direction and $\mathrm{e}$ is axial chord. $\mathrm{X}=0.0$ and 1.0 correspond to the blade leading edge and trailing edge respectively. As the two dimensionality of the flow was established by Govardhan et al. (1994) for the same cascade, the flow survey was studied over one half of the blade span from one side wall up to midspan. The X-axis of the contour plots represents the distance from the end wall $(\mathrm{Z})$ nondimensionalised with the full blade span $(400 \mathrm{~mm})$. The $\mathrm{Y}$-axis represents the non-dimensional distance between pressure and suction surfaces.

The contours of local loss coefficient for without fence case are shown in Fig. 5. The loss is more in the wake region than the rest of the passage. The loss coefficient increases drastically towards the end wall while having a large loss core at about $Z / h=0.04$. The large loss 
core is a result of an amalgamation of pressure side leg of the horseshoe vortex (hence inlet boundary layer fluid) and passage vortex (hence cross channel boundary layer). Horseshoe vortex is formed around the leading edge near the end wall. The cascade geometry and the inlet flow field determine the passage pressure distribution and the nature of secondary flow. The mainstream fluid flow interacts with secondary flow and results in a new flow field which can be quantitatively examined by the formation and interaction of the horseshoe vortex, saddle point of separation, passage vortex and the end wall boundary layer cross flows. Outside the wake region and end wall region (after $Z / h=0.125$ ) losses are more or less equal in magnitude.

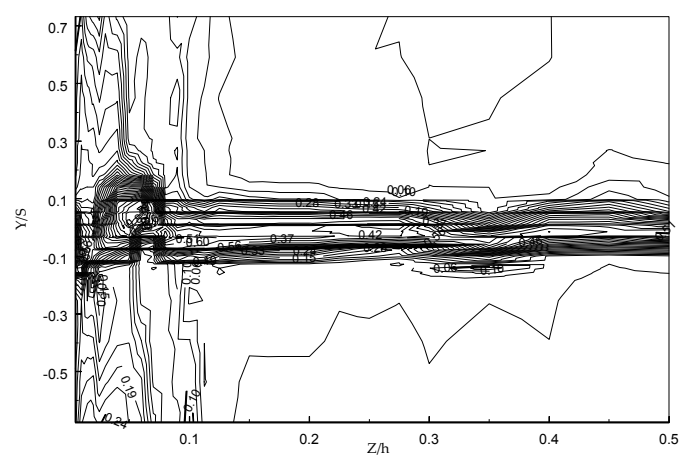

Fig. 5. Contours of local loss coefficient (without fences)

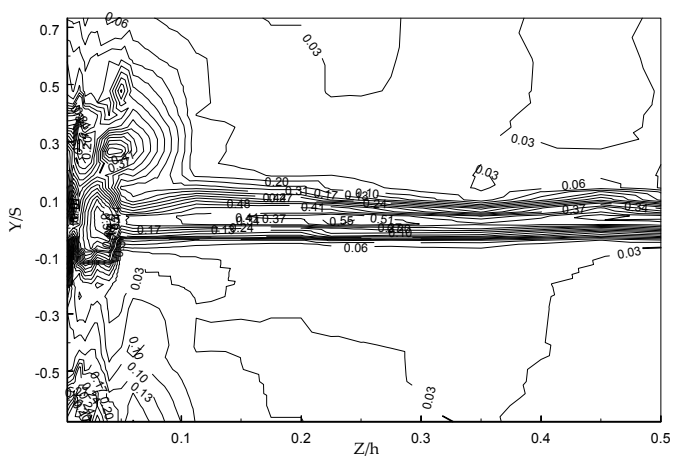

Fig. 6. Contours of local loss coefficient with fence of $12 \mathrm{~mm}$ height

The contour plot of local loss coefficients with the fences of $12 \mathrm{~mm}$ height is shown in Fig. 6. It can be seen that the large loss core as well as the loss near the end wall is reduced. The fence has effectively prevented the movement of pressure side leg of the horseshoe vortex and hence the accumulation of low energy fluid on the suction surface is minimized. With fences of $12 \mathrm{~mm}$ height, boundary layer thickness is reduced compared to normal blade case. Furthermore; the losses due to corner vortex are slightly reduced by the fences, as expected from the weakening of the end wall cross-flow. The contour of local loss coefficients with fence of $16 \mathrm{~mm}$ height is plotted in the Fig. 7. The contours are almost same as in the case with fence of 12 $\mathrm{mm}$ height. In this case the high loss core has further reduced and it has split in to two small loss cores. The loss coefficient is reduced because of reduction in the boundary layer thickness and resulting in overall reduction of loss in the end wall region.

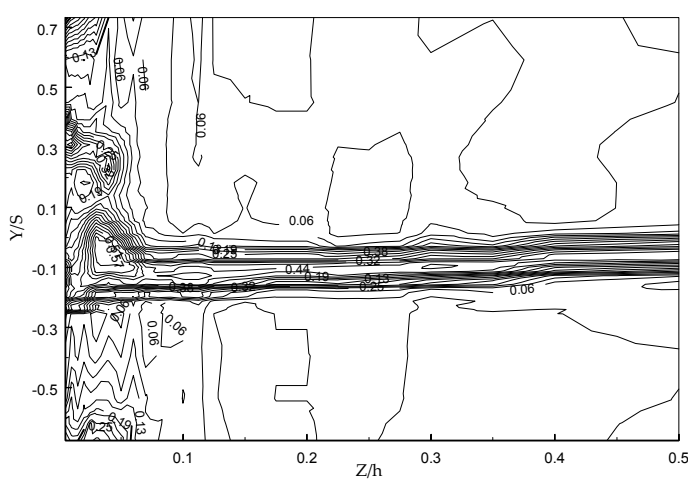

Fig. 7. Contours of local loss coefficient with fence of $16 \mathrm{~mm}$ height

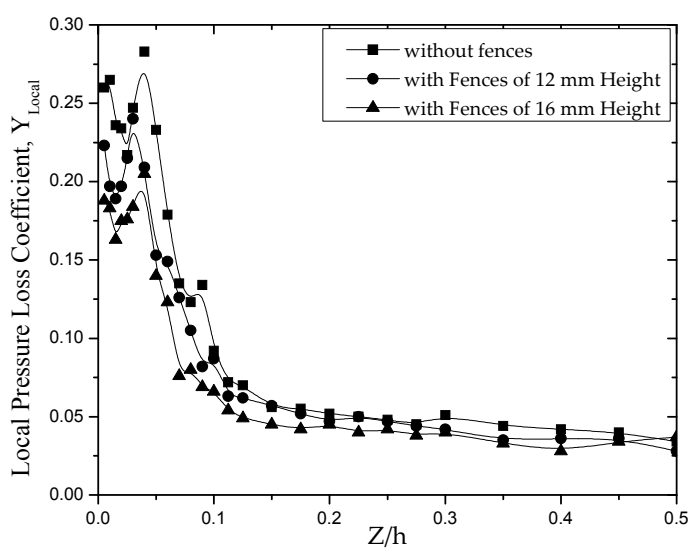

Fig. 8. Spanwise distribution of pitchwise mass averaged loss coefficient

Using fences, the strength of the passage vortex and the loss associated with it has decreased. These aspects are clearly seen when the pitchwise mass averaged total pressure loss coefficient is presented. The local loss coefficients were pitchwise mass averaged, and the distribution of it along the span of the blade is shown in Fig. 8. The losses are maximum slightly away from the end wall due to end wall boundary layer. The end wall boundary layer loss is less when fences are incorporated. The loss peak without fence case occurs at $Z / h=0.04$ with a magnitude of 0.28 . When the fences are fixed half pitch away from the blades, the loss peak magnitude is reduced to $0.24,0.19$ for fence heights of $12 \mathrm{~mm}$, and $16 \mathrm{~mm}$ respectively. With streamwise fences, the loss core not only reduced in magnitude but also moved slightly away from the suction surface. The fences effectively prevented the movement of pressure side leg of the horseshoe vortex and hence the accumulation of low energy fluid on the suction surface is minimized. The fences are effective in preventing the vortex from growing to its full strength and shifted the vortex core from the suction surface resulting in lesser aerodynamic losses in the passage. Reduced losses result in improved performance.

\subsection{Exit Flow Angle}

The inlet boundary layers splits into two sections and forms horseshoe vortex at a point known as saddle point which is located at the blade's leading edge and 
end wall junction (see Fig.1 for details). Two sections moves either side of the blade, the one that moves towards pressure side of the blade is called pressure side leg and the other that moves towards suction side is called suction side leg. As pressure side leg of horseshoe vortex enters the passage, it is influenced by blade to blade pressure gradient which enables it to drifts towards the adjacent suction surface and mixes with the blade's suction side leg. The drifting action of the pressure side leg is known as end wall cross flow. Both the side legs rotate opposite to each other and forms the passage vortex which travels along the blade's suction surface and through the passage. The outcome of the passage vortex is change in flow angle which results in change in work output.

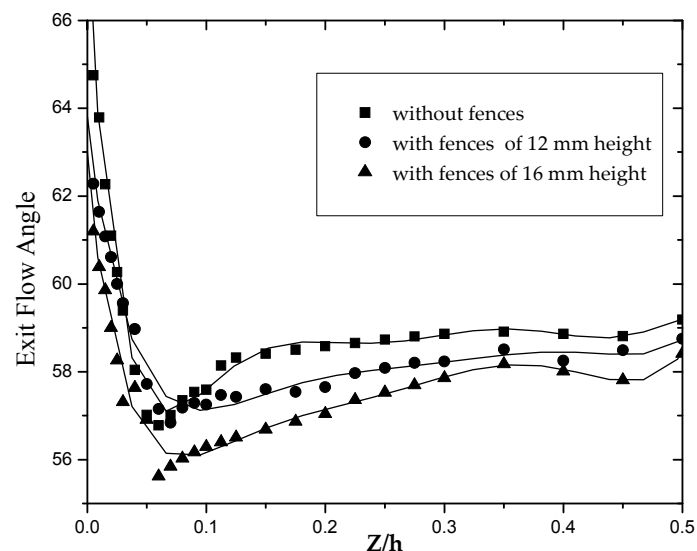

Fig. 9. Spanwise distribution of pitchwise mass averaged exit flow angle

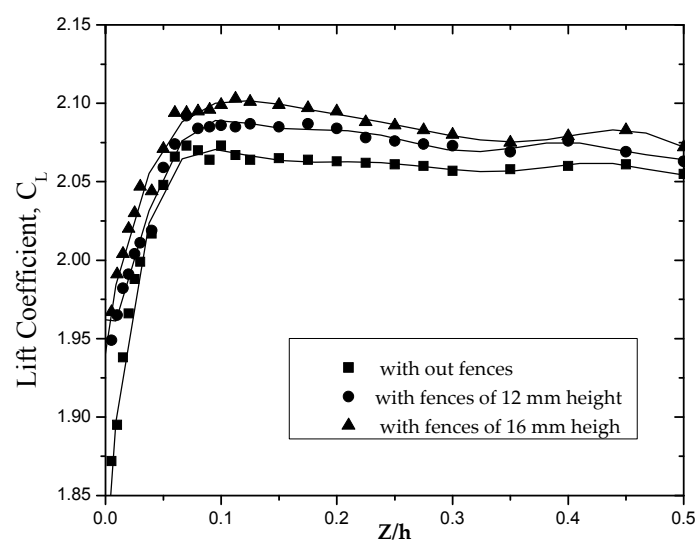

Fig. 10. Spanwise distribution of pitchwise mass averaged lift coefficient

The blade angle at the inlet is $22^{\circ}$ and at the exit angle is $-60^{\circ}$. The exit angle increases close to end wall. In a passage, whenever turning of fluid occurs, a balance is established between the static pressure gradients and the centrifugal forces in the fluid. The pressure varies across the passage from one surface of a blade to another surface of the nearest blade.

By radial equilibrium theory, it is assumed that for a turbine with annulus wall parallel to the axis, the flow streamlines upstream and downstream of a blade row lie on concentric cylinders. Also a flow radial shift takes places within the blade row. The relationship between the free stream velocity, radial static pressure gradient and the radius of the curvature of the streamline gives required information about the flow direction. The relationship can be written as

$\frac{\rho C^{2}}{r_{c}}=\frac{d p}{d r}$

Where $\mathrm{C}$ is freestream velocity and $r_{c}$ is radius of curvature.

Towards the end wall, the velocity decreases within the boundary layer. The reduced kinetic energy becomes insufficient to balance the imposed pressure gradient and the radius of curvature of streamline becomes less resulting in overturning of the flow. The term 'overturning' is used to denote the flow deflection, which is larger than the expected geometric deflection of the blade. If the flow deflection is less than the geometric deflection of the blade, it is referred to as 'underturning'.

The spanwise distribution of pitchwise mass averaged exit flow angles for all three cases (with and without fences) is plotted in Fig. 9. The mass averaged angle for normal blade (without fences) case overturns by about $7^{\circ}$ on the end wall. The overturn is reduced to about $5^{\circ}$ and $4^{\circ}$ for fences of heights $12 \mathrm{~mm}$ and $16 \mathrm{~mm}$ respectively. The amount of underturning in the region of loss core is affected by the presence of fences. When the fences are incorporated, flow underturns more and the midspan angle is also slightly reduced by the presence of fences. From spanwise distribution, the flow angle has maximum slope near the end wall region. The flow underturning decays faster towards the midspan when the fences are incorporated.

\subsection{Lift and Drag Coefficients}

When a blade is submerged in a flow field, there are interaction forces between the blade and flow field. These forces are due to the pressure and the viscous shear stress distributions summed up over entire surface between the blade and flow field. The forces are usually separated into a component parallel to the free stream velocity, which is called drag force, and a component perpendicular to the free stream velocity, that is called lift force. These two forces are proportional to density of the flow medium, square of the flow velocity, and the area of the blade. The lift and drag for a particular flow field are usually expressed as dimensionless parameters called the drag and lift coefficients.

The local lift and drag coefficients are pitchwise mass averaged to get the spanwise distribution. The variation of lift and drag coefficients along the span of the blade are plotted in Figs. 10 and Fig. 11. Figure 10 shows spanwise distribution of drag coefficient along the span of the blade. The drag coefficient is more near the end wall for without fences, compared to fences height of $12 \mathrm{~mm}$ and $16 \mathrm{~mm}$ respectively. The peak without fences occurs at $Z / h=0.04$ with a magnitude of 0.21 . The peak reduces to $0.16,0.15$ for fences heights of 12 $\mathrm{mm}$, and $16 \mathrm{~mm}$ respectively. Reduction in total pressure losses with fences is primary reason for the reduction in drag coefficient. The drag coefficient is more in the loss core region. From Fig. 11, it is clear that the lift coefficient is significantly less in the 
boundary layer. Near the end wall, $C_{D}$ is very high, hence $C_{L}$ is expected to be less. The lift coefficient gradually increases from the end wall and remains more or less constant after about $Z / h=0.09$.

Table 2 Effect of streamwise fences on total pressure loss coefficient, lift and drag coefficients

\begin{tabular}{|l|l|l|l|}
\hline & $Y_{\text {Total }}$ & $C_{D}$ & $C_{L}$ \\
\hline Without fence & 0.075 & 0.071 & 2.06 \\
\hline With fences of 12 mm height & 0.064 & 0.063 & 2.07 \\
\hline With fences of 16 mm height & 0.056 & 0.056 & 2.08 \\
\hline
\end{tabular}

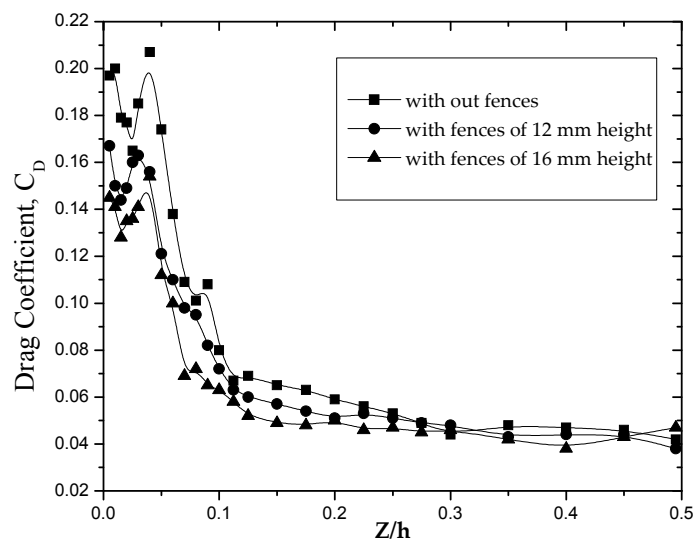

Fig. 11. Spanwise distribution of pitchwise mass averaged drag coefficient

The overall effect of streamwise fence on reduction of total losses is shown in Table 2. The total loss is reduced by $15 \%, 25 \%$ for fences heights of $12 \mathrm{~mm}$ and $16 \mathrm{~mm}$ respectively compared to without fence case. Due to reduction in the total pressure loss, a corresponding change is obtained in drag and lift coefficients.

\section{Conclusion}

Fences effectively reduce the strength of the large loss core leading to lesser aerodynamic losses in the turbine passage. This resulted in reduced total pressure losses within the boundary layer. The total pressure loss is reduced by $15 \%, 25 \%$ for fences heights of $12 \mathrm{~mm}$ and $16 \mathrm{~mm}$ respectively. Due to reduction in the total pressure loss, a corresponding change was obtained in drag and lift coefficients. Spanwise distribution of exit flow angle without fences indicates that the fluid flow overturns by about $7^{\circ}$ near the end wall while it slightly underturns in the loss core region. Overturning in the flow is reduced by about $5^{\circ}$ and $4^{\circ}$ for fences heights of $12 \mathrm{~mm}$ and $16 \mathrm{~mm}$ respectively.

In overall, it could be concluded that fences reduce the secondary losses and improve the turbine cascade performance.

\section{REFERENCES}

Aunapu, N.V., R.J. Volino, K.A. Flack and R.M. Stoddard (2000). Secondary flow measurements in a turbine passage with end wall flow modification. ASME J. of Turbomachinery 122, 651-658
Chung, J.T. and T.W. Simon (1993). Effectiveness of the gas turbine endwall fences in secondary flow control at elevated freestream turbulence levels. ASME Paper No. 93-GT-51

Govardhan, M., A. Rajender and J.P. Umang (2006). Effect of streamwise fences on secondary flows and losses in a two-dimensional turbine rotor cascade. Journal of Thermal Science 15, 296-305.

Govardhan, M., N. Venkatrayulu and V.S. Vishnubhotla (1994). Influence of tip clearance on the inter blade and exit flow field of a turbine rotor cascade, ASME Paper No. 94-GT-35, 1-8.

Kawai, T. (1994). Effect of combined boundary layer fences on turbine secondary flow and losses. JSME International Journal 37, 377-384.

Moon, Y.J. and S.R. Koh (2001). Counter rotating streamwise vortex formation in the turbine cascade with endwall fence, Computer \& Fluids 30, 473490 .

Wang, H.P., S.J. Olson, R.J. Goldstein and E.R.G. Eckert (1997). Flow visualisation in a linear turbine cascade of high performance turbine blades, ASME Journal of Turbomachinery 119, 18. 